\title{
Robust least square approach for optimal development of quadratic fuel quantity function for steam power stations
}

\author{
Ikenna Onyegbadue ${ }^{1}$, Cosmas Ogbuka ${ }^{2,3}$, Theophilus Madueme ${ }^{2}$ \\ ${ }^{1}$ Department of Electrical and Computer Engineering, Igbinedion University, Okada, Nigeria \\ ${ }^{2}$ Department of Electrical Engineering, University of Nigeria, Nsukka, Nigeria \\ ${ }^{3}$ Africa Centre of Excellence for Sustainable Power and Energy Development (ACE-SPED), University of Nigeria, Nsukka, Nigeria
}

\begin{tabular}{l}
\hline Article Info \\
\hline Article history: \\
Received Oct 30, 2021 \\
Revised Dec 1, 2021 \\
Accepted Dec 22, 2021 \\
\hline
\end{tabular}

Keywords:

Bi-square

Ordinary least square

Quadratic fuel quantity

Robust least square

Root mean square error

Valve point loading

\begin{abstract}
Ordinary least square (OLS) and robust least square (RLS) consisting of least absolute residual and $\mathrm{Bi}$-square approaches were deployed to obtain the fuel consumption characteristic curve and the coefficients of the quadratic fuel consumption function for thermal stations in Nigeria. Results were compared based on convergence property, root mean square error, R-square value, adjusted R-square value, and width interval of coefficients. Valve Point loading effects of Egbin and Sapele power stations were used to develop the quadratic fuel consumption characteristic curve and function. The average difference in width interval for the coefficients $\mathrm{a}, \mathrm{b}, \mathrm{c}, \mathrm{d}$, and $\mathrm{e}$ of the two stations, after comparing Bi-square and OLS technique, were $0.02084,8.5055,1856.565,520.8855$, and 0.0082 , respectively. The Rsquare values obtained from the Bi-square technique were superior to the OLS technique with arithmetic differences of 0.6196 and 0.5254 for Egbin and Sapele generating stations, respectively. Bi-square technique also offered better adjusted R-square value for Egbin and Sapele stations with arithmetic differences of 0.622 and 0.5287 , respectively. Bi-square technique offered smaller root mean square error than the ordinary least square technique for both stations. The coefficients obtained from Bi-square technique were used to develop the fuel quantity function for the studied stations.
\end{abstract}

This is an open access article under the CC BY-SA license.

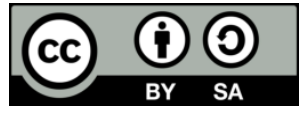

\section{Corresponding Author:}

Cosmas Ogbuka

Department of Electrical Engineering, University of Nigeria

Nsukka, Nigeria

Email: cosmas.ogbuka@unn.edu.ng

\section{INTRODUCTION}

The operating cost is a vital aspect of electrical energy production and it constitutes the economics of the operation. The optimal solution to power flow and economic dispatch problems have become critical and are now considered research issues in modern power systems [1]-[3]. These problems are formulated mathematically and their solutions are optimize based on fuel cost function subject to various operational constraints [4]-[7]. The solution obtained from solving these problems will save generating costs, especially in fossil fuel plants.

The fuel cost function which is commonly represented by a quadratic function is affected by many factors vis, the ambient temperature of operation and the rate of aging of the generating units. It is a significant issue to accurately estimate the thermal unit fuel cost curve parameters periodically [8]. Therefore, using a reliable and powerful estimation technique in the estimation of parameters of fuel cost curve is very imperative. 
Mathematical methods have become a vital technique for estimating coefficients and data fitting. It has become a measure for statistical inference [9]. Till date, only few works have been done on the estimation of fuel cost curve parameters. In the past decades, several techniques were employed in solving the complex fuel cost problem. Each method has its own advantages and disadvantages. Different mathematical models were used to represent the fuel cost function [8]. The basic principle of the OLS method is to estimate the parameter vectors, by minimizing the sum of squares of errors in order to find the best function that matches a set of data [10]-[12]. Least square techniques aim at reducing the sum of squared errors between the obtained data and the actual data and has been used for state estimation in power system [13]-[16]. Taylor's series expansion principle of the least squares error curve fitting technique was used to estimate power system frequency and amplitude [17]. Least square technique has found diverse applications in electrical engineering such as in power quality assessment [18], determine symmetrical components of power system [19], phasor estimation for power quality monitoring [20], to mention but a few.

Economic dispatch problem is a problem of power system management that can be solved when the fuel quantity function of thermal plants is obtained. The ordinary least-square (OLS) method was used to develop fuel quantity functions of thermal generating plants [21], [22]. Although, the accuracy of OLS is threatened by the presence of outliers in data set [23]. The need to explore the benefits of robust techniques for the development of quadratic fuel function of thermal plants becomes key. In order to optimally manage thermal generating stations, the coefficients of quadratic fuel quantity function must be uniquely determined. Most literature obtained these coefficients using the ordinary least square technique that is sensitive to extreme values. This has motivated me to use the robust technique. This study is aimed at developing the quadratic fuel quantity function of steam power stations with a focus on Egbin and Sapele power stations both in the Nigeria power grid. The objective of this work include the development of the coefficients (a, b, c, d, e) of the fuel quantity function while considering the effect of valve point loading and accessing the goodness-of-fit of function developed.

\section{FORMULATION OF LEAST SQUARE MODEL FOR FUEL QUANTITY FUNCTION OF THERMAL STATION}

Consider the polynomial to degree $\mathrm{n}$ for a functional relationship between $\mathrm{x}$ and $\mathrm{y}$.

$$
\begin{aligned}
& y=a_{0}+a_{1} x+a_{2} x^{2}+\cdots a_{n} x^{n} \\
& y=\sum_{j=0}^{n} a_{j} x^{j}
\end{aligned}
$$

For a set of $\mathrm{N}$-data points $\left(x_{i}, y_{i}\right)$, given a set of points $\left(x_{1}, y_{1}\right),\left(x_{2}, y_{2}\right),\left(x_{3}, y_{3}\right), \ldots,\left(x_{n}, y_{n}\right)$ the least square estimates of $a_{0}, a_{1}, a_{2}, \ldots, a_{n}$ can be obtained in a similar way as that of linear regression. The sum of squared deviation of the values of $y$ from predicted value is given by [24].

$$
S=\sum\left(y-a_{0}-a_{1} x-a_{2} x^{2} \ldots a_{n} x^{n}\right)^{2}
$$

In (3) can be minimized by setting its partial derivatives with respect to (4).

$$
a_{0}, a_{1}, a_{2}, \ldots, a_{n}=0
$$

The following equation is obtained:

$$
\sum y=a_{0}+a_{1} \sum x+a_{2} \sum x^{2} \ldots a_{j} \sum x^{j}
$$

the cost function for the thermal stations in Nigeria can be described with the (6) [25], [26].

$$
F_{i}\left(P_{G i}\right)=\sum_{i=1}^{n}\left(a_{i} P_{G i}^{2}+b_{i} P_{G i}+c_{i}\right)
$$

Where $a_{i}, b_{i}$, and $c_{i}$ are coefficients of the $i^{t h}$ generating station. $n$ is the total number of thermal stations and $P_{G}$ is the power generated by the $i^{\text {th }}$ generating station.

For Valve Point Loading effect consideration which is the case of Egbin and Sapele steam power stations, in (6) can be modified thus:

$$
F_{i}\left(P_{G i}\right)=\sum_{i=1}^{n}\left(a_{i} P_{G i}^{2}+b_{i} P_{G i}+c_{i}+\left|d_{i} \sin \left(e_{i}\left(P_{G i}^{\min }-P_{G i}\right)\right)\right|\right)
$$


hence, the sum square error is given by (8).

$$
s=\sum_{i=1}^{n}\left(y_{i}-\left(a P_{i}+b P_{i}+c+\left|d \sin \left(e\left(P^{\min }-P_{i}\right)\right)\right|\right)^{2}\right.
$$

In order to develop optimal coefficients for the objective fuel cost function of the steam thermal stations, the robust least square algorithm (Bi-square algorithm) is used to minimize (8) via the following steps:

1) Fit the model by weighted least squares;

2) Compute the adjusted residuals and standardize them. The adjusted residuals are given by (9);

$$
r_{\text {adjusted }}=\frac{r_{i}}{\sqrt{1-z_{i}}}
$$

$r_{i}$ are the usual least-squares residuals and $z_{i}$ are leverages that adjust the residuals by reducing the weight of high-leverage data points having a large effect on the least-squares fit. The standardized adjusted residuals are given by (10);

$$
u=\frac{r_{\text {adjusted }}}{C S}
$$

$\mathrm{C}$ is the tuning constant $=4.685$

$\mathrm{S}$ is the robust standard deviation

3) Compute the robust weights as a function of $u$. The Bi-square weights are given by (11);

$$
w_{i}=\left\{\begin{array}{cc}
\left(1-\left(u_{i}\right)^{2}\right)^{2} & \left|u_{i}\right|<1 \\
0 & \left|u_{i}\right| \geq 1
\end{array}\right\}
$$

4) Perform the next iteration of the fitting procedure by returning to the first step if the computation fails to converge at first iteration.

\section{DEVELOPMENT OF FUEL QUANTITY FUNCTION}

The fuel quantity consumed by the stations and their power output are compiled using Microsoft Excel Package. This data which constitutes the input-output data for the stations is used to develop the input-output characteristic curve using curve fitting tools in MATLAB 2017 model. The coefficients of fuel quantity function are obtained from the curve alongside the 'goodness of fit'.

\subsection{Egbin power station}

The relationship between the quantity of fuel utilized by the station and the power output from the generator (input-output relationship) is described by the graph in Figure 1. This relationship curve is obtained using the ordinary least square approach (OLS). The goodness of fit is described thus: R-square $=0.3651$; adjusted R-square=0.3626; RMSE $=2364$. The residual plot can be seen in Figure 2. This plot shows how much the outliers differ from the fitted model.

The relationship between the fuel input and power output for the generating station is obtained using a robust least square approach known as Bi-square. The relationship curve is shown in Figure 3 . The goodness of fit is described thus: R-square $=0.9847$; adjusted R-square=0.9846; RMSE $=367.1$. The residual plot can be seen in Figure 4.

After the test carried out on the three approaches (OLS and Bi-square), the Bi-square approach produced the best goodness of fit. It had a lower RMSE, a higher R-square and a higher adjusted R-square than the OLS approach. Hence, the coefficients together with the width intervals obtained from the $\mathrm{Bi}$-square approach are thus; $\mathrm{a}=4.288 \mathrm{e}-05(0.0010728)$

$\mathrm{b}=12.09(1.64)$

$\mathrm{c}=11.1(616.6)$

$\mathrm{d}=6.447(150.43)$

$\mathrm{e}=0.1453(0.0152)$

The quadratic fuel quantity function for Egbin power generating station is given thus:

$$
F_{13}\left(P_{13}\right)=0.00004288 P_{13}^{2}+12.09 P_{13}+11.1+\left|6.447 \sin \left(0.1453\left(P_{13}^{\min }-P_{13}\right)\right)\right|
$$

from the curve fitting, 


$$
P_{13}^{\min }=68.9 \mathrm{MW}
$$

hence, (8a) can be modified thus;

$$
F_{13}\left(P_{13}\right)=0.00004288 P_{13}^{2}+12.09 P_{13}+11.1+\left|6.447 \sin \left(0.1453\left(68.9-P_{13}\right)\right)\right|
$$

these coefficients were computed with $95 \%$ confidence bound.

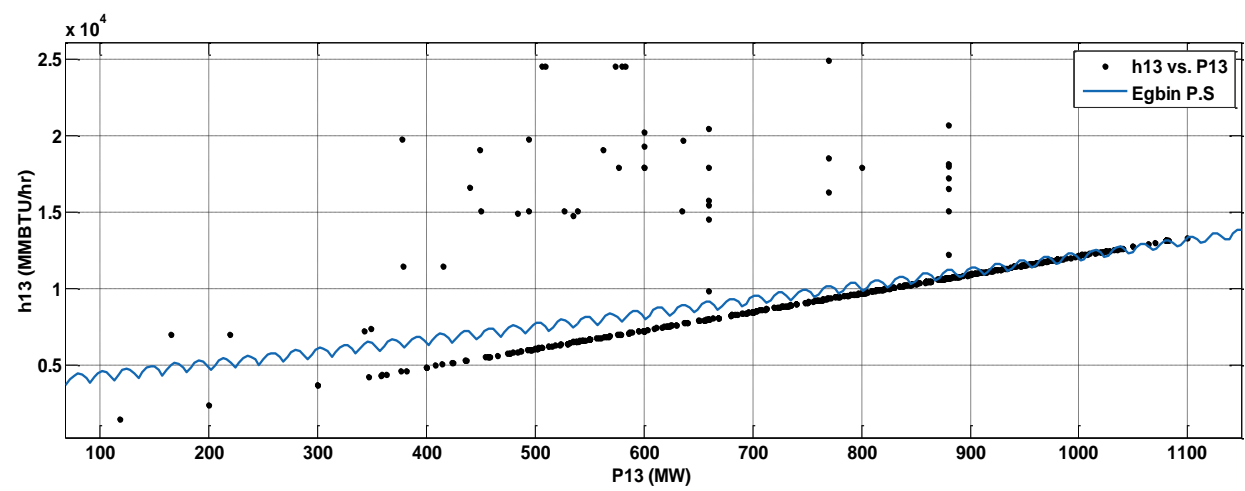

Figure 1. Input-output curve for Egbin power generating station (OLS)

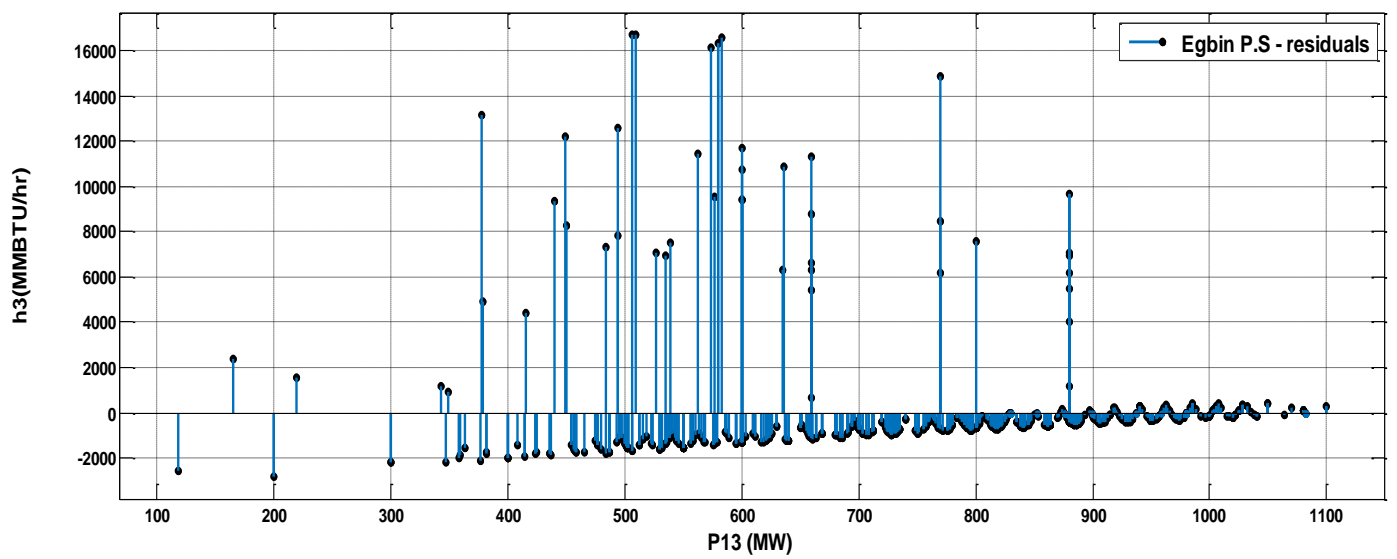

Figure 2. The residual plot from the input-output characteristics curve of Egbin power station

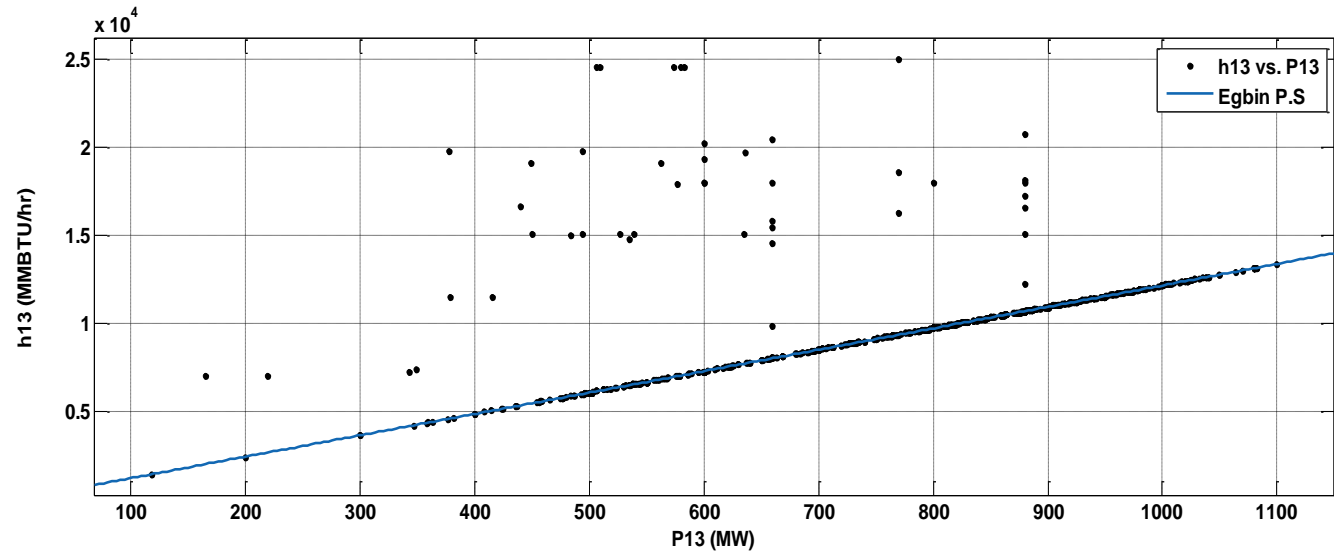

Figure 3. Input-output curve for Egbin power station (Bi-square) 


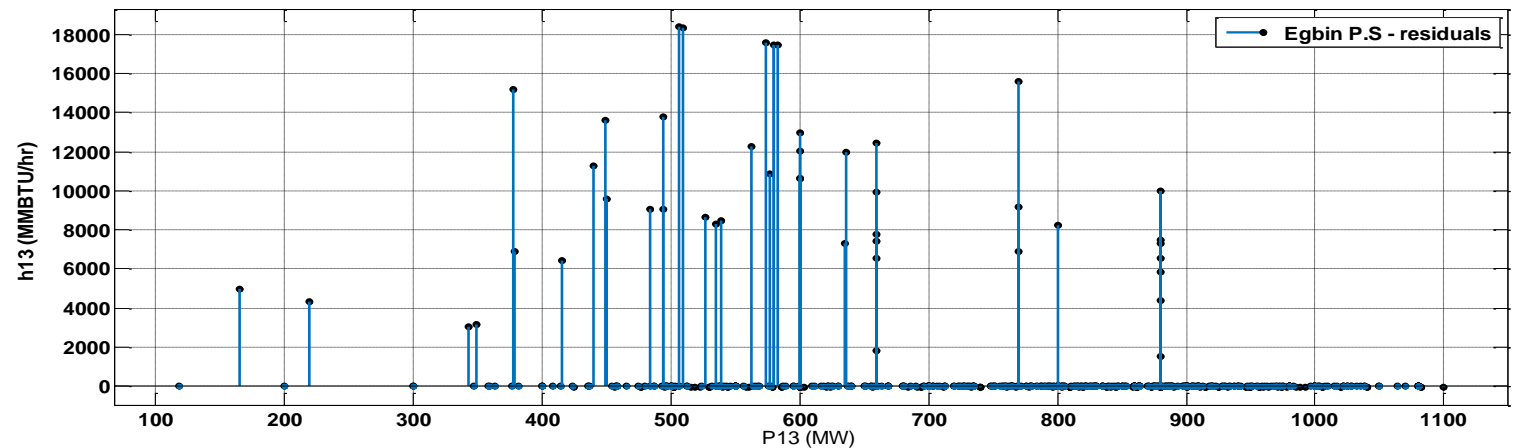

Figure 4. The residual plot from the input-output characteristics curve of Egbin power generating station

\subsection{Sapele steam power generating stations}

The relationship between the quantity of fuel utilized by the station and the power output from the generator (input-output relationship) is described by the graph in Figure 5. This relationship curve is obtained using the ordinary least square approach (OLS). The fuel input which is measured in MMBTU/hr is represented by the vertical axis (h14). The power output from the station is represented by the horizontal axis (P14). The goodness of fit is described thus: R-square=0.453; adjusted R-square=0.4496; RMSE=296.1.

The residual plot can be seen in Figure 6. This plot shows how much the outliers differ from the fitted model. The relationship between the fuel input and power output for the generating station is obtained using a robust least square approach known as Bi-square. The relationship curve is shown in Figure 7 . The goodness of fit is described thus: R-square $=0.9784$; adjusted R-square=0.9783; RMSE=58.77; The residual plot can be seen in Figure 8 .

After the test carried out on the two approaches (OLS and Bi-square), the Bi-square approach produced the best goodness of fit. It had a lower RMSE, a higher R-square and a higher adjusted R-square than the OLS approach. Hence, the coefficients as well as the width intervals obtained from the Bi-square approach are thus: $\mathrm{a}=0.002837(0.0089360)$

$\mathrm{b}=8.989(2.022)$

$\mathrm{c}=23.29(105.27)$

$\mathrm{d}=18.38(28.739)$

$\mathrm{e}=0.5412(0.01)$

The quadratic fuel quantity function for Sapele Steam power generating station is given thus;

$$
F_{14}\left(P_{14}\right)=0.002837 P_{14}^{2}+8.989 P_{14}+23.29+\left|18.38 \sin \left(0.5412\left(P_{14}^{\min }-P_{14}\right)\right)\right|
$$

from the curve fitting, $P_{14}^{\min }=23.48 M W$

hence, (9a) can be modified as (13b).

$$
F_{14}\left(P_{14}\right)=0.002837 P_{14}^{2}+8.989 P_{14}+23.29+\left|18.38 \sin \left(0.5412\left(23.48-P_{14}\right)\right)\right|
$$

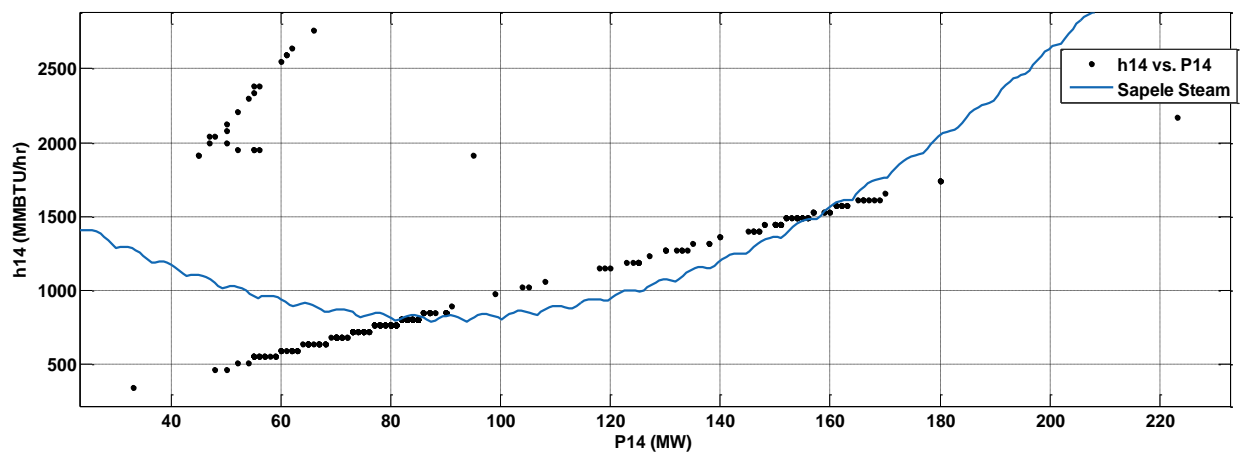

Figure 5. Input-output curve for Sapele steam power generating station (OLS) 


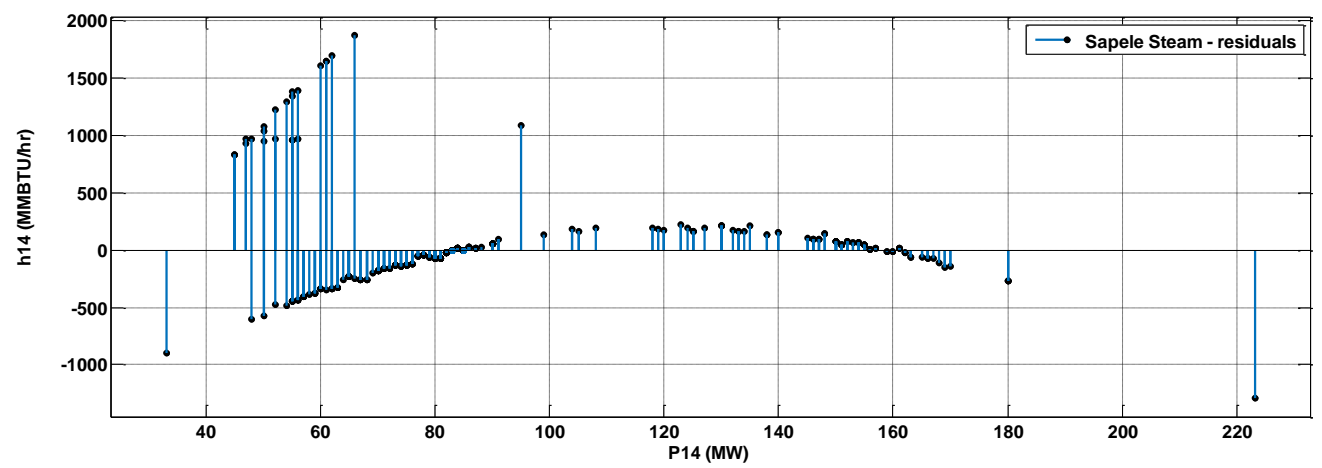

Figure 6. The residual plot from the input-output characteristics curve of Sapele steam power station

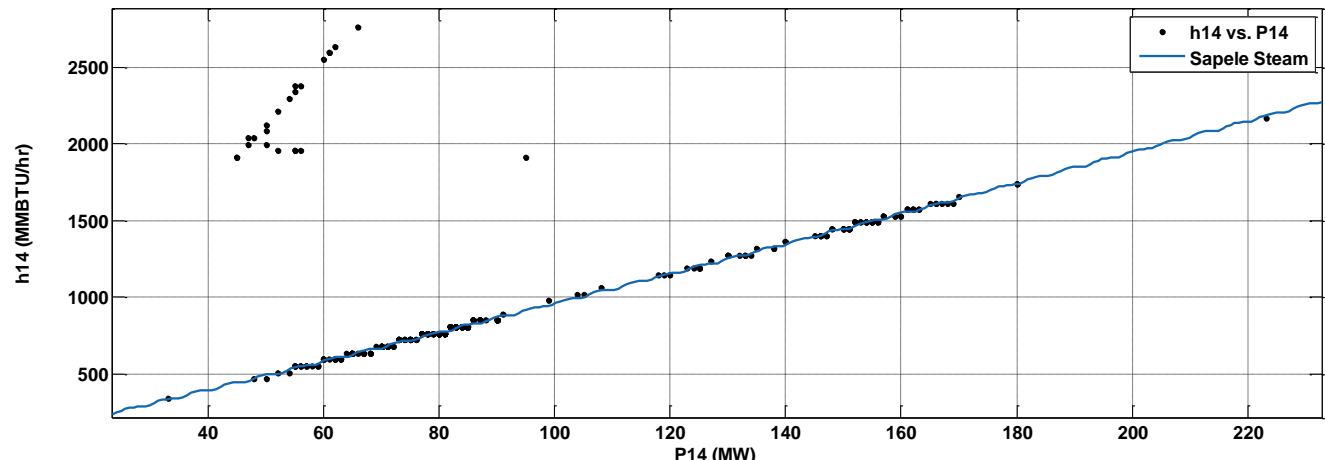

Figure 7. Input-output curve for Sapele steam power station (Bi-square)

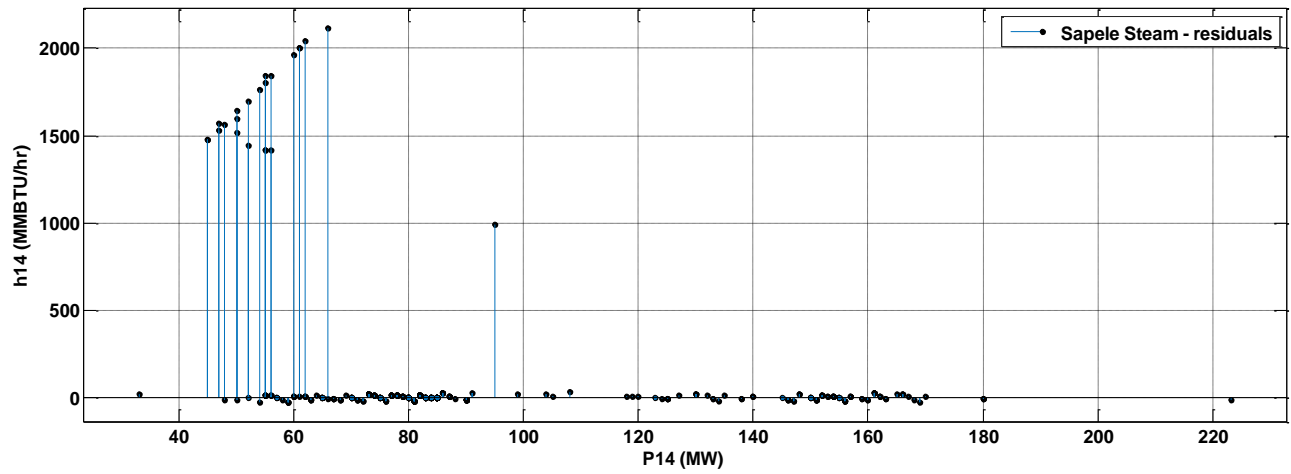

Figure 8. The residual plot from the input-output characteristics curve of Sapele steam power generating station

The width interval of the fuel quantity coefficients for the generating stations is contained in Table 1. Width interval is another indicator for goodness of fit. A smaller interval indicates a better fit. From Table 1, it can be seen that bi-square offers a narrower width interval. After comparing both techniques for Egbin generating station, the differences in width interval (OLS value-Bi-square value) for the various coefficients were as follows; a-coefficient was 0.0058102 , b-coefficient was 8.863 , c-coefficient was 3288.4 , d-coefficient was 919.87 and e-coefficient was 0.0056 . The differences in width interval for the various coefficients obtained by comparing both techniques for Sapele steam station were as follows; a-coefficient was 0.035864 , b-coefficient was 8.148, c-coefficient was 424.73, d-coefficient was 121.901 and e-coefficient was 0.0108 . After considering the difference in width interval for the coefficients of both stations, average values were obtained thus; a-coefficient was 0.02084 , b-coefficient was 8.5055 , c-coefficient was 1856.565 , d-coefficient was 520.88550 and e-coefficient was 0.0082. The implication of this result is that the 
coefficients obtained from the Bi-square technique have a lower degree of uncertainty as compared with the results from OLS because they have a narrower width interval. Therefore, Bi-square technique produced a better fit than the ordinary least square technique.

Table 1. Width interval of fuel quantity coefficients for generating stations (hydro-thermal plant)

\begin{tabular}{cccccccccccc}
\hline \multirow{2}{*}{ S/No. Generating Station } & \multicolumn{2}{c}{ A } & \multicolumn{2}{c}{ B } & \multicolumn{2}{c}{ C } & D & \multicolumn{4}{c}{ E } \\
& Bi-Square & OLS & Bi-Square & OLS & Bi-Square & OLS & Bi-Square & OLS & Bi-Square & OLS \\
\hline 1 & Egbin & 0.0010728 & 0.006883 & 1.64 & 10.503 & 616.6 & 3905 & 150.43 & 1070.3 & 0.0152 & 0.0208 \\
2 & Sapele Steam & 0.008936 & 0.0448 & 2.022 & 10.17 & 105.27 & 530 & 28.739 & 150.64 & 0.01 & 0.0208 \\
\hline
\end{tabular}

A summary table showing the goodness of fit parameters for the curve fitting of the thermal stations is shown in Table 2. The arithmetic differences between the R-square values obtained from the two techniques were 0.6196 and 0.5254 for Egbin and Sapele power stations respectively. The arithmetic differences between the adjusted R-square values obtained from the two techniques were 0.622 and 0.5287 for Egbin and Sapele power stations respectively. The Bi-square technique offered a better 'goodness of fit' parameters than the ordinary least square approach.

The R-square and adjusted R-square values obtained from the Bi-square technique were better than that of the OLS technique for Egbin and Sapele generating stations because the values for the Bi-square technique were closer to 1 than that of the OLS technique. The RMSE values obtained from the Bi-square technique were less than that from OLS technique hence, Bi-square technique offered a better fit.

Table 2. Goodness of fit for the curve fitting of thermal plants (steam power plants)

\begin{tabular}{cccccccc}
\hline \multirow{2}{*}{ S/No } & \multirow{2}{*}{ Generating Station } & \multicolumn{2}{c}{ R-Square } & \multicolumn{2}{c}{ Adjusted R-Square } & \multicolumn{2}{c}{ RMSE } \\
& & Bi-Square & OLS & Bi-Square & OLS & Bi-Square & OLS \\
\hline 1 & Egbin & 0.9847 & 0.3651 & 0.9846 & 0.3626 & 367.1 & 2364 \\
2 & Sapele Steam & 0.9784 & 0.4530 & 0.9783 & 0.4496 & 58.77 & 296.1 \\
\hline
\end{tabular}

\section{RESULTS}

It was seen that the the width intervals for the various coefficients were narrower with the Bi-square technique hence indicating that the degree of uncertainty in obtaining the coefficients was low as compared with the OLS technique. It was also observed that the R-square and adjusted R-square values (coefficient of determination) obtained by using the Bi-square technique were closer to 1 than that of the OLS technique. The RMSE values obtained from the Bi-square technique were less than that of the OLS technique.

\section{CONCLUSION}

This work compared two classes of techniques used for the development of the quadratic fuel quantity for the different thermal stations in Nigerian $330 \mathrm{kV}$ power system network. The Bi-square approach which is a robust least square technique offered better performance in terms of its goodness of fit when compared with the ordinary least square approach. The Bi-square algorithm produced the best fitting when compared with the ordinary least square approach.

In the case of Egbin power station and sapele steam power station, the Bi-square technique produced a better width interval for coefficients $a, b, c, d$, and e. The difference in width interval obtained by comparing both techniques for Egbin power station is as follows: The difference in width interval obtained by comparing both techniques for Egbin power station produced the following values; 0.0058102, 8.863, 3288.4, 919.87 and 0.0056 for a, b, c, d, and e coefficients respectively. The difference in width interval obtained by comparing both techniques for Sapele steam power station gave a value of $0.035864,8.148$, 424.73, 121.901, and 0.0108 for a, b, c, d, and e coefficients respectively. These values were obtained based on the width interval of fuel quantity coefficients for generating stations (hydro-thermal plant).

The Bi-square offered better R-square for Egbin and Sapele steam power stations with an arithmetic difference of 0.6196 and 0.5254 respectively. $\mathrm{Bi}$-square also offered better adjusted $\mathrm{R}$-square value for Egbin and Sapele power stations with a difference of 0.622 and 0.5287 . Bi-square also produced smaller root mean square error than the ordinary least square technique for both stations. The arithmetic differences were obtained using the goodness of fit for the curve fitting of thermal plants (steam power plants). The valve point loading effect of Egbin power station and Sapele steam power stations were considered during the development of the quadratic fuel quantity characteristics. The quadratic fuel quantity characteristics developed can be used as building blocks for carrying out economic dispatch operations. 


\section{ACKNOWLEDGEMENTS}

The authors acknowledge the support received from the Africa Centre of Excellence for Sustainable Power and Energy Development (ACE-SPED), University of Nigeria, Nsukka that enabled the timely completion of this research.

\section{REFERENCES}

[1] L. Li, Y. Yang, M. L. Tseng, C. H. Wang, and M. K. Lim, "A novel method to solve sustainable economic power loading dispatch problem," Ind. Manag. Data Syst., vol. 118, no. 4, pp. 806-827, 2018, doi: 10.1108/IMDS-04-2017-0145.

[2] J. H. Woo, L. Wu, J. -B. Park, and J. H. Roh, "Real-Time Optimal Power Flow Using Twin Delayed Deep Deterministic Policy Gradient Algorithm," in IEEE Access, vol. 8, pp. 213611-213618, 2020, doi: 10.1109/ACCESS.2020.3041007.

[3] S. Khunkitti, A. Siritaratiwat, and S. Premrudeepreechacharn, "Multi-objective optimal power flow problems based on slime mould algorithm," Sustainability, vol. 13, no. 13, 2021, pp. 7448, doi: 10.3390/su13137448.

[4] T. T. Nguyen, C-T. Nguyen, L. V. Dai, and N. V. Quynh, "Finding optimal load dispatch solutions by using a proposed cuckoo search algorithm," Math. Probl. Eng., vol. 2019, 2019, doi: 10.1155/2019/1564693.

[5] M. H. R. Nascimento, J. de A. B. Junior, C. A. O. de Freitas, N. M. Moraes, and J. C. Leite, "Analysis of the solution for the economic load dispatch by different mathematical methods and genetic algorithms: Case Study," Journal of Engineering and Technology for Industrial Applications, vol. 4, no.15, pp 5-13. 2018, doi: 10.5935/2447-0228.20180041.

[6] O. Zebua, I. M. Ginarsa, and I. M. A. Nrartha, "GWO-based estimation of input-output parameters of thermal power plants," TELKOMNIKA Telecommunication, Computing, Electronics and Control, vol. 18, no. 4, pp. 2235-2244, 2020, doi: 10.12928/TELKOMNIKA.v18i4.12957.

[7] R. Keswani, H. K. Verma, and S. K. Sharma, "Dynamic Economic Load Dispatch Considering Renewable Energy Sources using Multiswarm Statistical Particle Swarm Optimization," 2020 IEEE International Conference on Computing, Power and Communication Technologies (GUCON), 2020, pp. 405-410, doi: 10.1109/GUCON48875.2020.9231171.

[8] M. Vanithasri, R. Balamurugan, and L. Lakshminarasimman, "Modified radial movement optimization (MRMO) technique for estimating the parameters of fuel cost function in thermal power plants," Int. J. Eng. Sci. Technol., vol. 19, no. 4, pp. 2035-2042, 2016, doi: 10.1016/j.jestch.2016.07.012.

[9] C. Wang, L. Qi, Y. Chen, and G. Pang, "A simple method for processing data with least square method," in 14th Conference on Education and Training in Optics and Photonics, vol. 10452, 2017.

[10] J. Bell, "Ordinary least squares revolutionized: establishing the vital missing empirically determined statistical prediction variance," SSRN, pp. 1-8, 2020, doi: 10.2139/ssrn.2573840.

[11] M. S. Peprah and I. O. Mensah, "Performance evaluation of the ordinary least square (ols) and total least square (tls) in adjusting field data: an empirical study on a DGPS data," South African Journal of Geomatics, vol. 6. no. 1, pp. 73-89, April 2017.

[12] J. Huang, Y. Zhang, X. Yang, and Z. Luo, "Transfer Function Model Identification Based on Improved Least Square Method," 2020 Chinese Automation Congress (CAC), 2020, pp. 487-491, doi: 10.1109/CAC51589.2020.9327337.

[13] M. B. D. C. Filho, J. C. S. de Souza, and J. D. Glover, "Roots, achievements, and prospects of power system state estimation: A review on handling corrupted measurements," Int. Trans. Electr. Energy Syst., vol. 29, no. 4, pp. 1-17, 2019, doi: 10.1002/etep.2779.

[14] A. Sharma and S. K. Jain, "A Review and Performance Comparison of Power System State Estimation Techniques," 2018 IEEE Innovative Smart Grid Technologies - Asia (ISGT Asia), 2018, pp. 770-775, doi: 10.1109/ISGT-Asia.2018.8467861.

[15] P. Puviya and N. Priyadarshini, "State estimation in power system using weighted least squares method," 2017 International Conference on Innovations in Information, Embedded and Communication Systems (ICIIECS), 2017, pp. 1-6, doi: 10.1109/ICIIECS.2017.8276038.

[16] H. Chi, "A Discussions on the Least-Square Method in the Course of Error theory and Data Processing," 2015 International Conference on Computational Intelligence and Communication Networks (CICN), 2015, pp. 486-489, doi: 10.1109/CICN.2015.100.

[17] R. B. Sharmaa and G. M. Dhole, "Least error squares approach: a practical method for power system frequency and amplitude estimation," Procedia Technology, vol. 25, pp. 710-717, 2016, doi: 10.1016/j.protcy.2016.08.164.

[18] M. Lu, "Power quality prediction based on least squares method," Vibroengineering Procedia, vol. 12, pp. 153-158, 2017, doi: 10.21595/vp.2017.18636.

[19] B. Rehman, C. Liu, and L. Wang, "Least square method: a novel approach to determine symmetrical components of power system," Journal of Electrical Engineering and Technology, vol. 12, no. 1, pp. 39-44, 2017, doi: 10.5370/JEET.2017.12.1.039.

[20] Y. Amirat, Z. Oubrahim, G. Feld, and M. Benbouzid, "Phasor estimation for power quality monitoring: Least square versus Kalman filter," IECON 2017 - 43rd Annual Conference of the IEEE Industrial Electronics Society, 2017, pp. 4339-4343, doi: 10.1109/IECON.2017.8216746.

[21] D. K. Setiawan and R. Anggraeni, "Analysis of input-output characteristic and generation cost optimization using quadratic least square regression and dynamic genetic algorithm method: case study PT.PLN PJB UP Gresik," in AIP Conference Proceedings, vol. 1818 , no. 1 , 2017. doi: $10.1063 / 1.4979942$

[22] D. M. D. Narv'aez, G. C. V'elez, and D. F. D. Narv'aez, "Application of the gradient method in the economic dispatch," Contemp. Eng. Sci., vol. 11, no. 96, pp. 4761 - 4768, 2018, doi: 10.12988/ces.2018.89513.

[23] D. O'Driscoll and D. E. Ramirez, "Limitations of the Least Squares Estimators; A Teaching Perspective," in ATINER's Conference Paper Series, Athens, 2016.

[24] K. Molugaram and G. S. Rao, Statistical techniques for transportation engineering, Amsterdam, Netherlands: Elsevier Inc., 2017.

[25] O. Aydin, S. S. Tezcan, I. Eke, and M. C. Taplamacioglu, "Solving the optimal power flow quadratic cost functions using vortex search algorithm," IFAC-PapersOnLine, vol. 50, no. 1, pp. 239-244, 2017, doi: 10.1016/j.ifacol.2017.08.040.

[26] S. O. Okozi, G. C. Ogbonna, M. Olubiwe, and E. O. Ezugwu, "Solution to the Economic Dispatch Problem of the Nigerian Power System using Genetic Algorithm," Nigerian Journal of Technology, vol. 38, no. 4, p. 1036 -1047, 2019, doi: 10.4314/njt.v38i4.29. 


\section{BIOGRAPHIES OF AUTHORS}

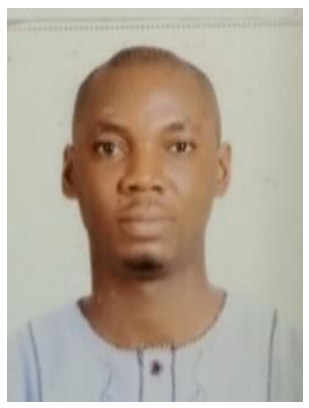

Ikenna Onyegbadue (D) Bd SC P obtained a B.Eng. degree (First Class Honors) in 2011 from the Department of Electrical and Computer Engineering, Igbinedion University Okada. He obtained a Master degree in Electrical Engineering (Power Systems option) from the Department of Electrical Engineering, University of Nigeria Nsukka in 2014 and is currently pursuing a Doctor of Philosophy (Ph.D) degree in Electrical Engineering from the same institution. He is a lecturer at the Igbinedion University Okada. He can be contacted at email: onyegbadue.ikenna@iuokada.edu.ng.

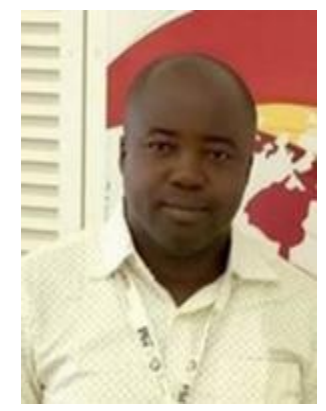

Cosmas Ogbuka (iD 8 SC $\mathrm{P}$ holds the following degrees from the Department of Electrical Engineering, University of Nigeria Nsukka, where he has attained the rank of Associate Professor: B.Eng. (First Class Honors), M.Eng. (Distinction) and Doctor of Philosophy (Ph.D.) obtained in 2004, 2009, and 2014 respectively. His research interests include Electrical Machines, Drives and Power Electronics. He is an International Faculty Fellow of the Massachusetts Institute of Technology (MIT) USA and had also undertaken a postdoctoral research visit at the Chair of Electrical Drives and Actuators (EAA) Universitaet der Bundeswehr Muenchen Germany. He is the Director of the Computer Communications Centre of the University of Nigeria. He can be contacted at email: cosmas.ogbuka@unn.edu.ng.

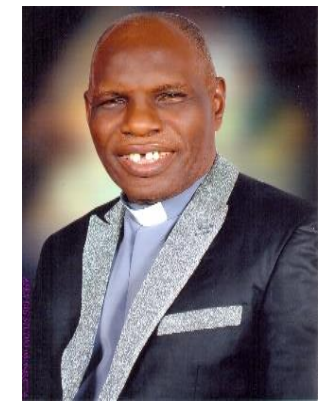

Theophilus Madueme (D) 81 SC P has M.Sc. from Chalmers Sweden in 1979 and a Ph.D from the University of Nigeria, Nsukka, Nigeria in 1994. He is a fellow of the Nigerian Society of Engineers (FNSE) and the Nigerian Institute of Electrical and Electronics Engineers (FNIEEE). He was the Dean of the Faculty of Engineering, University of Nigeria, Nsukka between 2012 and 2014. He is a Professor of Electrical Engineering. His research interests include Electric Power Systems, High Voltage Engineering and Renewable Energy Systems. He has taught undergraduate and postgraduate courses in Electric Power Systems and High Voltage Engineering. He has been a supervisor of Nine Ph.D students to graduation. He has published over 78 academic papers. He can be contacted at email: theophilus.madueme@unn.edu.ng. 